\title{
STATISTICS OF MULTIPLE SCLEROSIS*
}

INCLUDING A STUDY OF THE INFANTILE, CONGENITAL, FAMILIAL AND HEREDITARY FORMS AND THE MENTAL AND PSYCHIC SYMPTOMS

\section{S. WECHSLER, M.D.}

Assaciate in Neurology, Columbia University; Adjunct Attending Neurologist, the Mt. Sinai Hospital and Associate Visiting Neurologist,

the Montefiore Hospital

NEW YORK

This study is based on the records of 1,970 cases of multiple sclerosis. Of the total, 1,773 represent cases culled from literature and 197 those whose records I have personally studied. Of the latter, fifty-five are from the Vanderbilt Clinic, ninety-three from the Mount Sinai Hospital and forty-nine from the Montefiore Hospital.

The object of the investigation was to determine the comparative incidence of the disease in the United States and Europe, the ages (including the ages of onset), average duration, sex, civil status, occupation and nativity. Special study was made of cases reported as hereditary, congenital, familial and infantile. Although the matter of personality (psychic and mental manifestations) does not come within the purview of a statistical study, attention was paid to this aspect of the symptomatology of the disease.

With the exception of a few recent reports in the literature, most of the statistical records date back many years, especially those which have appeared in this country. The diagnosis of multiple sclerosis was more rigidly dependent on the Charcot triad in the earlier days and many reports date back to the time when the Babinski phenomenon was unknown and when the significance of absent abdominals in multiple sclerosis was not appreciated. The more elastic conception of the disease on the part of European (more especially German) neurologists may account for some of the differences in the reported comparative incidence of the disease. It may be said, too, that critical study of case reports frequently leads one to doubt the diagnosis. This is especially true of cases recorded as infantile, congenital, hereditary and familial. I have therefore taken special pains to study, as far as was possible, the histories of many of the cases of multiple sclerosis recorded in the literature, which bore on statistics, especially those of the last mentioned group. I reviewed each of the 197 records of the cases which make up my own study. Another point of importance

* Read before the Association for Research in Nervous and Mental Diseases, New York, December, 1921. 
is that, with very few exceptions, all the diagnoses of multiple sclerosis are made on clinical and not on pathologic grounds.

Discrepancies occur in the various totals because the statistics recorded in the literature are not uniform. Some investigators merely refer to the percentage incidence, others speak only of sex, still others only of ages or duration: American records are especially meager, and with the exception of Jeliffe's, ${ }^{1}$ rather incomplete. This makes comparison between American and European statistics somewhat uneven; nevertheless, there is a sufficient number of records for a fairly satisfactory comparison. Perhaps it should be pointed out that the continental statistics cover practically the whole of Europe, whereas the

TABle 1.-Number of Cases in the United States

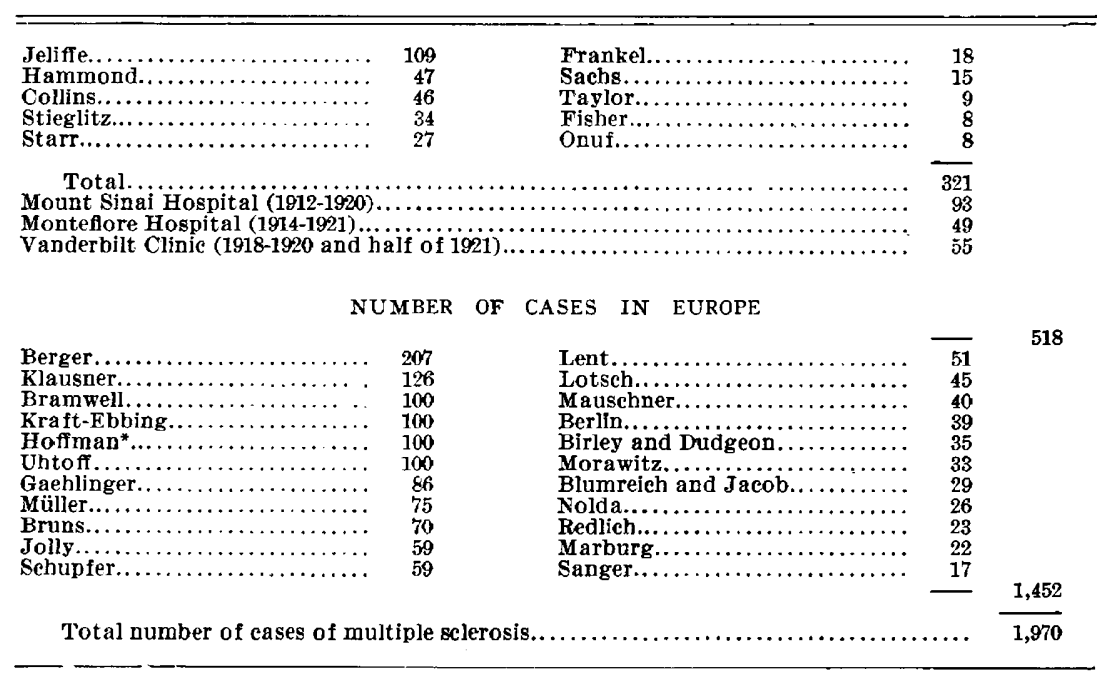

* Hoffman, J.: Die multiple Sklerose des Centralnervensystems, Deutsch. Ztschr. f. Nervenh. $21: 1,1901-1902$

American statistics, if not limited to New York City, embrace only a small part of the country. Some of the totals recorded by European observers, especially in the infantile group, embrace a number of cases which have been included by other compilers in their study of statistics. By referring to the originals and by cross references I have tried to avoid recording the cases more than once.

\section{TOTAL NUMBER OF CASES}

Of the 1,970 cases recorded, 518 are from America and 1,452 from Europe. Deducting the 197 cases personally studied there remain 321 American cases whose records date back many years, none being more

1. Jeliffe, S. E.: Multiple Sclerosis: Its Occurrence and Etiology, J. Nerv. \& Ment. Dis. 31:446 (July) 1904. 
recent than 1903. Most of the European statistics are not any more recent, but they are spread over a greater number of years.

\section{INCIDENCE}

In America multiple sclerosis usèd to be looked on as a rare disease. Recent records prove that it is not so uncommon in this country as was formerly believed. Morawitz ${ }^{2}$ states that it is the most common organic nervous disease in rural populations and gives the following figures: multiple sclerosis thirty-three cases, tabes twenty and cerebrospinal syphilis ten. Cassirer ${ }^{3}$ says that next to tabes and syphilis of the nervous system multiple sclerosis is the most common disease. Müller ${ }^{4}$ also speaks of it as the most common organic disease. Neither gives figures. These statements are not quite borne out by my records. While there were forty-nine cases of multiple sclerosis in the Montefiore Hospital between 1914 and 1921, there were 167 cases of syphilis of the nervous system divided as follows: tabes eighty-five, general paresis seventeen and cerebrospinal syphilis sixty-five. In the Mount Sinai Hospital there were 562 cases of syphilis of the nervous system to ninety-three of multiple sclerosis, almost 6 to 1 , divided thus: tabes 160, general paresis eighty-five and cerebrospinal syphilis 317 . It should be explained that the Mount Sinai figures are not statistically conclusive for the reason that during the period covered special study of syphilis of the nervous system was carried on and effort was made to admit an unusual number of cases.

The highest percentage recorded in Europe is that by Mauschner ${ }^{5}$ in the Tubingen Clinic, that is, 2.5. The lowest by Jolly (Berlin) as 0.84 . Williams of England gives a percentage of 2.2. The highest of the older American statistics is that of Frankel, 1.7 and the lowest by Taylor ${ }^{6} 0.09$, even if we include his doubtful cases. ${ }^{7}$ Frankel's figures were high because they represented the incidence among organic cases only. The recent Montefiore Hospital records (1914-1921) show a percentage incidence of 4.3 while the recent Mount Sinai Hospital records (1912-1920) give 2.9 per cent. Both these figures, repre-

2. Morawitz, P.: Zur Kenntness der multiplen Sklerose, Deutsch. Arch. f. klin. Med. 82:151, 1904-1905.

3. Cassirer, R.: Ueber eine besondere Lokalisations-und Verlaufsform der multiplen Sklerose, Monatsch. f. Psychiat. u. Neurol. 17:193, 1905. Die multiple Sklerose in Wichtigsten Nervenkrankheiten in Einzeldarstellung, Leipzig, 1915.

4. Müller, Eduard: Die multiple Sklerose des Gehirns und Ruckenmarks, Jena, 1904.

5. Mauschner, Ernest: Multiple Sklerose und Unfall, Arch. f. Psychiat. 3: 1917.

6. Taylor, E. W., and Meyer, J. W.: Boston M. \& S. J. 148:393, 1903.

7. Unless otherwise mentioned, the percentages stated refer to the total number of cases both organic and functional. 
senting ward (organic) cases, are lower than Bramwell's, ${ }^{8}$ which are 5.5 per cent. for all ward cases (also presumably only organic). Bramwell's figures for all clinic patients are 1.7 per cent.

Computing all the European records together we get an average incidence of 1.33 per cent., while all the old American records gave only 0.36 per cent. These figures may be compared with what Bramwell found in 1903, that is $1: 82$, or 1.2 per cent., in Europe, and $1: 219$, or 0.46 per cent, in the United States. The recent American figures

TaBle 2.-Percentage of Incidence in the United States

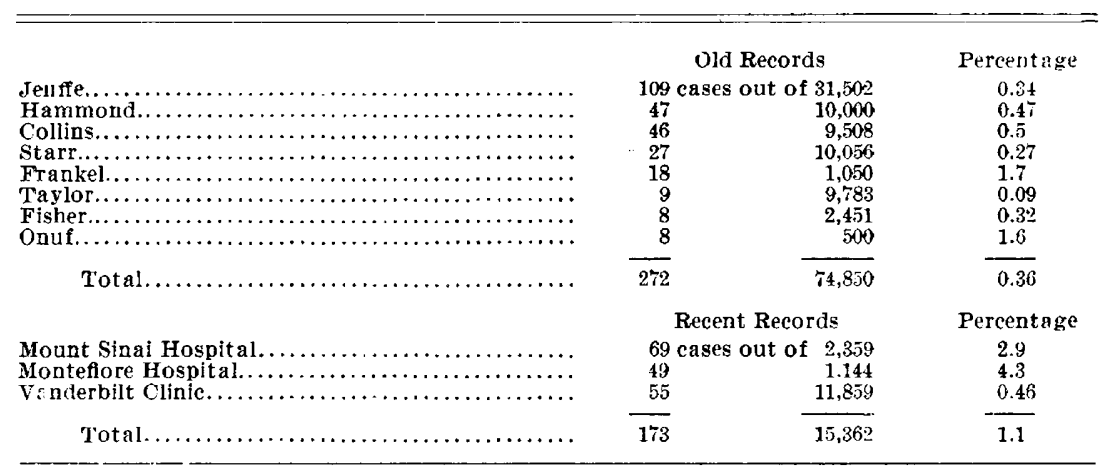

TABLE 3.-Percentage of Incidence in Europe

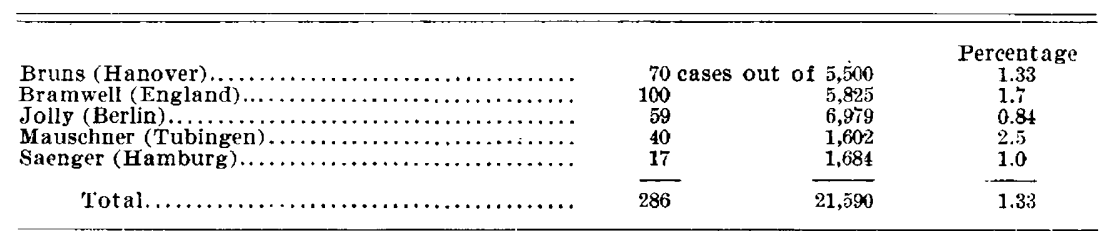

show a percentage of 1.1 of all cases, which is three times the old ones, and almost approaches the European. Combining the Mount Sinai and Montefiore records, ${ }^{9} 2.9$ per cent. and 4.3 per cent., respectively, we

8. Bramwell, Byrom: The Prognosis of Disseminated Sclerosis, Rev. Neurol. \& Psychiat. 3:161, 1905; Relative Frequency of Disseminated Sclerosis in Scotland and North of England and in America, ibid. 1:12, 1903.

9. It will be noticed that the Mount Sinai Hospital percentage is computed on a total of sixty-nine cases out of 2,359 , whereas the total number of histories of multiple sclerosis numbered ninety-three. This is because the diagnosis was doubtful in twenty-four cases, and I included only those in which it was absolutely certain clinically. The same applies to the Montefiore Hospital records; only of this group I excluded, besides doubtful cases, also records of patients who had previously been at the Mount Sinai Hospital. Had I included the latter, and for the purpose of computing the statistics of the Montefiore Hospital alone there is reason for doing so, the percentage incidence of that institution would have been considerably higher. 
get a percentage of 3.36 for organic cases. It will be seen, therefore, that the average incidence of multiple sclerosis in this country has risen considerably during the last twenty years; but whether due to more accurate diagnosis or extension of the disease concept or to actual numerical increase cannot be stated from the figures alone.

AGE

Multiple sclerosis occurs in all ages, from early childhood to very old age. It has been described in about 100 cases in children. (This will be discussed fully when we come to consider the infantile, congenital, familial and hereditary forms.) In the literature mention is made of patients as young as $11 / 2$ and 3 and 4 years. The youngest

TABLE 4.-Arris of Patients with Multiple Sclerosis

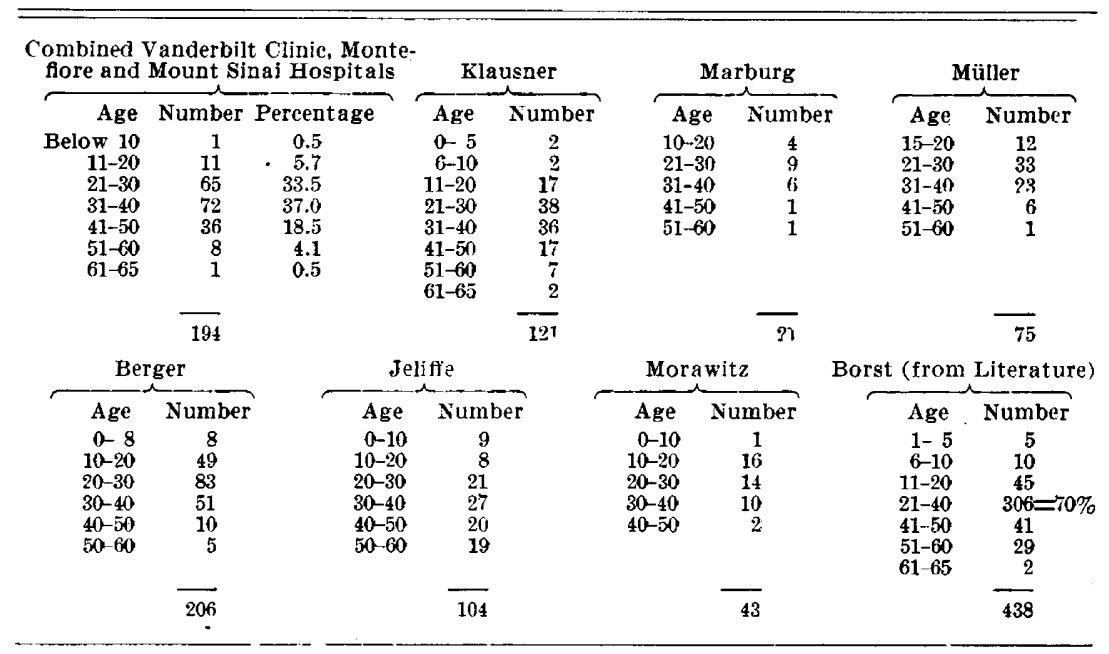

recorded by myself was 10 years, with the onset of the illness at 7 . Crocq (quoted by Jeliffe) speaks of a patient of 81 years, but in all other records no mention is made of patients above 65 . The disease is most common between the ages of 20 and 40 , about 70 to 75 per cent. of all cases. Cassirer thinks it is most common in the third decade. Of a total of 428 cases collected by Borst, ${ }^{10} 306$, or 70 per cent., were between 20 and 40. Birley and Dudgeon ${ }^{11}$ give the average age as 28.6 years. Jeliffe records an unusually large number between 50 and 60-18 per cent. Table 4 may serve for comparison.

10. Borst, Max: Die multiple Sklerose des Zentralnervensystems, in Lubarsch u. Ostertag: Ergebnisse der algemeinen Pathologie 9:66, 1903-1904.

11. Birley, J. L., and Dudgeon.L. S.: Clinical and Experimental Contribution to the Pathogenesis of Disseminated Sclerosis, Brain 44:150, 1921. 


\section{DURATION}

Two different notions are implied under the term duration. One refers to the length of the period from the onset of the first symptom to the time the patient comes under observation, the other is the total duration from the onset of the illness to death. The first, assuming it is always possible to tell the time of onset of the first symptom, is somewhat easier to estimate than the second, because most patients are not followed to the very end. Indeed nearly all the records refer to the first notion of duration. It is important to bear in mind these two different notions in the bearing they have on prognosis, because it is obvious that the same patient the duration of whose illness under the first concept is estimated, say, at six months, may still be alive twenty years hence, and in a subsequent study be classed under the second notion of duration.

TABLE 5.-DuRation OF ILlness

\begin{tabular}{|c|c|c|c|c|}
\hline & $\begin{array}{c}\text { Combined Vanderbilt Clinic, } \\
\text { Monteflore and } \\
\text { Mount Sinai Hospitals }\end{array}$ & - Bramwell & & \\
\hline Less than 6 months.................... & 31 & Patal Cases: & & \\
\hline 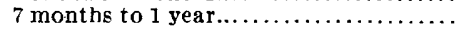 & 15 & $1-4$ years. & 10 & \\
\hline 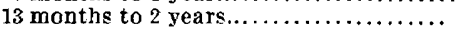 & 47 & $5-9$ years... & 13 & \\
\hline 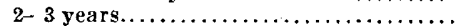 & 27 & $10-14$ years........... & 8 & \\
\hline 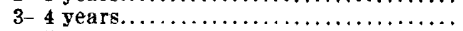 & 11 & $15-21$ years.......... & 4 & \\
\hline 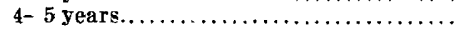 & 15 & & & 35 \\
\hline 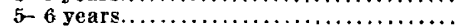 & 7 & Alive-Worse.... & & 33 \\
\hline $7-10$ years. $\ldots \ldots \ldots \ldots \ldots \ldots \ldots \ldots \ldots \ldots$ & 28 & Unimproved.. & & 16 \\
\hline $11-15$ years. $\ldots \ldots \ldots \ldots \ldots \ldots \ldots \ldots \ldots \ldots$ & 9 & Improved..... & & 8 \\
\hline 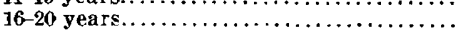 & 1 & Well.......... & & \\
\hline \multirow[t]{2}{*}{ 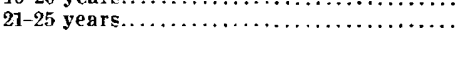 } & 1 & Unknown........... & & 14 \\
\hline & 192 & & & $\overline{110}$ \\
\hline
\end{tabular}

Birley and Dudgeon give the average duration from the onset of the illness to the time of examination as four years, the shortest being three weeks and the longest fourteen years. Marburg ${ }^{12}$ gives the duration in twenty-two cases he studied as from twenty-six days to thirteen months, one exception being three years. Bramwell gives the average duration in thirty-five fatal cases as seven years and nine months-(seven months to twenty-one years). He records the longest duration in a living patient as thirty-three years, and six cases between twenty and thirty years. My own records show one patient with a history of twenty-five years' duration. Five of my patients gave a history of one month or less. Comparative tables are given in the following.

12. Marburg, Otto: Die sogenannte akute multiple Sklerose (Encephalomyelitis periaxialis scleroticans), Jahrb. f. Psychiat. u. Neurol. 27:211, 1906. 
SEX

The male sex is more often affected than the female, in the ratio of nearly three to two. Of twenty-six records only six speak of greater incidence among females, the latter being those of Charcot, Berlin, Müller, Bruns ${ }^{x 3}$ and Stelting, Morawitz and Birley and Dudgeon.

TABLE 6.-Sex of Patients with Multiple Sclerosis

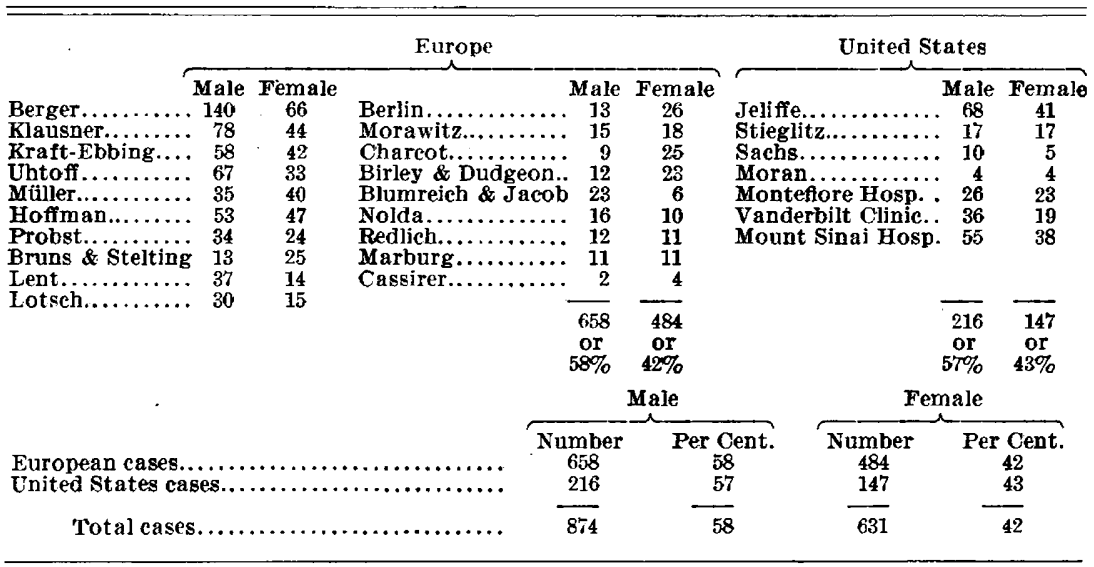

These figures represent about 15 per cent. of the total number of cases reviewed. The American and European statistics very nearly coincide in this respect.

\section{OCCUPATION}

Morawitz states that multiple sclerosis is most common in the rural (agricultural?) population. It is said to affect mainly the laboring class. My own statistics do not confirm either view, though it is hardly fair to contradict the first statement since all of my patients come from

Table 7.-Occupation of Patients

\begin{tabular}{llll}
\hline \hline Soldier & Pressman & Candymaker & Newsdealer \\
Cashier & Salesman & Student & Domestic \\
Teacher & Carpenter & Storekeper & Bellboy \\
Machinist & Houseworker & Weaver & Artist \\
Tailor & Roofer & Printer & Chaufleur \\
Pedler & Cook & Baker & Iron worker \\
Laborer & Clerk & Cigarmaker & Policeman \\
Painter & Driver & Bartender & \\
Cutter & Buteher & & \\
\hline
\end{tabular}

New York City. Practically every occupation is represented in my list of cases, as shown in Table 7. Obviously all general ward patients come from the working people.

13. Bruns, L.: Ueber die Erkrankungen der Sehnerven im Fruhstadium der multiplen Sklerose, Neurol. Zentralbl. 18:475, 1899. 


\section{NATIVITY}

The following figures are practically limited to New York City, and it is obviously not altogether true to speak of them as representative of the whole United States. There are more than four times as many cases among those of foreign birth as among natives. Even allowing for the great number of foreign born in New York-and they constitute roughly only two fifths of the population-it is difficult to account for the unusual excess of foreigners over natives. The fact in itself, however, may possibly account for the greater incidence of multiple sclerosis in Europe as compared to America, although in his study covering fifteen years (1888-1903) Jeliffe gives more nearly even figures: Forty-seven native and fifty-four foreign born. The following table refers to my own cases.

Table 8.-Nativity of Patients with Multiple Sclerosis

\begin{tabular}{|c|c|c|c|c|}
\hline \multirow[b]{2}{*}{$\begin{array}{l}\text { Mount Sinai Hospital } \ldots \ldots \ldots \ldots \ldots \ldots \ldots \ldots \ldots \ldots \\
\text { Montefiore Hospital. } \ldots \ldots \ldots \ldots \ldots \ldots \ldots \ldots \ldots \ldots \\
\text { Vanderbilt Clinic. } \ldots \ldots \ldots \ldots \ldots \ldots \ldots \ldots\end{array}$} & \multicolumn{2}{|c|}{ Native } & \multicolumn{2}{|c|}{ Foreign Born } \\
\hline & $\begin{array}{c}\text { Number } \\
11 \\
6 \\
19\end{array}$ & $\begin{array}{l}\text { Per Cent. } \\
11.8 \\
12.2 \\
34.5\end{array}$ & $\begin{array}{l}\text { Number } \\
82 \\
43 \\
36\end{array}$ & $\begin{array}{l}\text { Per Cent. } \\
88.2 \\
87.8 \\
65.5\end{array}$ \\
\hline 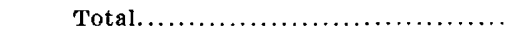 & 36 & 18.3 & 161 & 81.3 \\
\hline
\end{tabular}

CIVIL STATUS

Multiple sclerosis is more common among married people than among single ones, but this fact is accounted for by the greater incidence of the disease during the ages between 20 and 50 . The fact, therefore, cannot be said to have special significance. Except my own, there are no statistics bearing on this point.

TABLE 9.-Civil Status

\begin{tabular}{|c|c|c|c|c|}
\hline \multirow[b]{2}{*}{$\begin{array}{l}\text { Mount Sinai Hospital } \ldots \ldots \ldots \ldots \ldots \ldots \ldots \ldots \ldots \ldots \\
\text { Montefore Hospital. } \ldots \ldots \ldots \ldots \ldots \ldots \ldots \ldots \ldots \ldots \ldots \\
\text { Vanderbilt Clinic } \ldots \ldots \ldots \ldots \ldots \ldots \ldots \ldots \ldots\end{array}$} & \multicolumn{2}{|c|}{ Married } & \multicolumn{2}{|c|}{ Single } \\
\hline & $\begin{array}{l}\text { Number } \\
60 \\
23 \\
35\end{array}$ & $\begin{array}{l}\text { Per Cent. } \\
64.5 \\
60.5 \\
\quad 63.6\end{array}$ & $\begin{array}{l}\text { Number } \\
33 \\
15 \\
20\end{array}$ & $\begin{array}{l}\text { Per Cent. } \\
35.5 \\
39 . \overline{5} \\
36.4\end{array}$ \\
\hline Total $\ldots \ldots \ldots \ldots \ldots \ldots \ldots \ldots \ldots \ldots$ & 118 & 63.5 & 68 & 36.5 \\
\hline
\end{tabular}

\section{MULTIPLE SCLEROSIS IN CHILDREN}

Opinions vary as to the existence of multiple sclerosis in children. In alluding to four cases of early multiple sclerosis which he had seen (4, 7, 12 and 13 years, respectively) Oppenheim ${ }^{14}$ expressed the opinion, in 1887, that "the beginning of multiple sclerosis in adults

14. Oppenheim, H.: Zur Pathologie der disseminierten Sklerıse, Berl. klin. Wchnschr. 24:904 (Nov. 28) 1887. 
cannot infrequently be traced to the very earliest childhood." Müller states that "proof of the existence of infantile multiple sclerosis is still missing, but it may trace its beginning to childhood" and "the development of the process on the basis of a congenital predisposition (is) most likely." It may be pointed out that congenital predisposition is a vague expression, capable of numerous interpretations.

One of the early, exhaustive studies of infantile multiple sclerosis was made by Schupfer. ${ }^{15}$ He studied fifty-eight cases recorded in the literature up to 1902 and included one case of his own. This was in a child of 11, who at 9 had an acute illness with fever, coma, convulsions, paralysis and ocular palsies. Although Schupfer includes this case in his group of multiple sclerosis, it is obvious from the history, no matter what the clinical findings were at the time of the examination, that he was dealing with a case whose inception corresponds to a meningitis or meningo-encephalitis. Most of the cases he records are neither clinically nor pathologically multiple sclerosis. Congenital syphilis would account for many of them. Hereditary spinal spastic paralysis, Friedreich's ataxia, hereditary cerebellar ataxia, encephalitis, tumors of the brain, cerebral palsies of children, the Little and Foerster types, all these are represented in the group recorded by Schupfer. Nevertheless, it must not be inferred that this author has not critically analyzed his material; he would still include twenty-eight of the fiftynine cases as true instances of multiple sclerosis in children.

In 1909 Gaehlinger ${ }^{16}$ reviewed the histories of eighty-six cases of multiple sclerosis out of a total of ninety-one reported as having occurred in children below 15, some even in infancy. All the cases were taken from the literature and included those recorded by Schupfer (1902) and Baboneix (1904). Gaehlinger concluded that "none of the observations have given us absolute proof of the existence of infantile multiple sclerosis." This despite Oppenheim's ingenious theory that all multiple sclerosis begins in infancy and only manifests itself later in life. Gaehlinger also emphasizes the difficulty of diagnosis. To which may be added the unreliability of most histories, the unusual difficulty in tracing the onset of the earilest symptoms and the inability to exclude fever or infectious diseases as etiologic factors. The same author also mentions Friedreich's ataxia, chorea, Little's disease, cerebral sclerosis, family spastic paraplegia, tumors of the brain, disseminated syphilis (congenital), hysteria and encephalomyelitis, as more likely diagnoses. The recent epidemic of encephalitis justifies the addition of this disease as a likely possibility.

15. Schupfer, F.: Ueber die infantile Herdsklerose, Monatschr. f. Psychiat. u. Neurol. 12:61 and 89, 1902.

16. Gaehlinger, M. H.: Contribution à l'étude de la sclérose en plaque infantile, L'Echo méd. du Nord. 13:37 (Jan.) 1909. 
Eichhorst ${ }^{17}$. reviewed the literature up to 1896 . He mentioned the fourteen cases recorded by Marie up to 1883 , the nineteen by Unger up to 1887 and those by Nolda ${ }^{18}$ up to 1891 . Eichhorst added a case of his own, that of a boy of -8 . (His mother had multiple sclerosis, as was shown at necropsy.) The boy also died and came to necropsy. Microscopic section of the boy's cord showed multiple sclerosis. Of the other twenty-six patients only three came to necropsy. In those three instances the cord was not examined, and the reports show that other brain changes besides sclerosis were found. Nolda's case was that of a boy of 9 whose disease began at 7 and whose clinical picture was typical of multiple sclerosis. Weisenburg ${ }^{19}$ reported the cases of a girl of 4 and a boy of 15-brother and sister.

Armand-Delille ${ }^{20}$ described a case of multiple sclerosis in a child of 5. Raymond and Beaudouin ${ }^{21}$ reported the case of a girl of 13 whose symptoms began at 10 . Neither is conclusive. Raymond and Lejonne ${ }^{22}$ speak of a girl of 9 years whose condition was progressive and whose signs and symptoms were apparently those of multiple sclerosis. But the history was that of a disease with an acute onset which lasted three weeks, and leaves the question of meningitis unanswered. Stieglitz ${ }^{23}$ records three cases in which the patients were 9,11 and 15, respectively. All three are doubtful from the description of the clinical picture; but in fairness it must be said that the diagnosis of multiple sclerosis was definite in that author's mind.

Schuler, mentioned by Nolda, reported a case of multiple sclerosis in a child, which was proved by necropsy. Rauschburg, ${ }^{24}, 1909$, reported the case of a boy of 7 who had partial paraplegia, intention tremor and slight speech disturbance. The disease began at $1 \frac{1}{2}$ years of age; there was no history of previous illness and no hereditary factor. Although the case is not proved pathologically, the diagnosis seems not

17. Eichhorst, Herman: Ueber infantile u. hereditare multiple Sklerose, Virchows Arch. f. path. Anat. 146:173, 1896.

18. Nolda, August: Ein Fall von multipler Hirn-und Ruckenmarksklerose im Kindesalter, Arch. f. Psychiat. 23:565, 1891-1892.

19. Weisenburg, T. H.: Multiple Sclerosis. Its Occurrence in a Family, Arch. Diagnosis 2:167 (April) 1909.

20. Armand-Delille, M. P.: Symptoms de sclérose en plaques chez un enfant de cinq ans et demi, Rev. neurol, 13:243, 1905.

21. Raymond and Beaudouin: Sclérose enplaque infantile, Rev. neurol. 13: 647, 1905.

22. Raymond and Lejonne: Encephalomyelite consecutive a un etat meningé chez une fillette de 9 ans, Sclérose en Plaque? Rev. neurol. 17:367, 1909.

23. Stieglitz, L.: Multiple Sclerosis in Children, with a Report of Three Cases, J. Nerv. \& Ment. Dis. 24:174, 1897.

24. Rauschburg, P.: Ein kindischer Fall von Sklerosis multiplex, Neurol. Centralbl. 28:622, 1909. 
improbable. Schlesinger, ${ }^{25} 1909$, described the case of a boy whose history, signs and symptoms pointed to a subacute process. The diagnosis of disseminated sclerosis was made because of the multiplicity of symptoms and the eye signs (optic atrophy). Encephalomyelitis was considered as a possible cause. The patient died and came to necropsy. Macroscopic and mircoscopic study confirmed the diagnosis of subacute multiple sclerosis.

In my record from the Mount Sinai Hospital there is the history of a boy of 10 who was normal up to the age of $61 / 2$ when he developed sudden paralysis of the right arm and later of both legs. There was no fever, headache, vomiting or other symptoms of acute illness. Abdominal reflexes were absent; there was a left Babinski sign and normal electrical reactions. He recovered from this attack and within the next three years had four others in which he had ataxia, tremor, the Babinski sign and laughing spells, and the abdominal reflexes were absent. Fairly good recovery followed each attack. The remissions, together with the signs and symptoms, seemed to justify the diagnosis of multiple sclerosis. In the Montefiore Hospital records there is the history of a girl of 18 whose illness began at the age of 8 with difficulty in walking, weakness of the hands, incontinence of urine. Physical examination revealed a spastic gait, tremor of both hands, lively deep reflexes, bilateral clonus, a Babinski sign and the absence of abdominal reflexes. Clinically there seems to have been no question as to the diagnosis of multiple sclerosis. Another case is that of a young woman of 27, the onset of whose illness dates back definitely to the age of 13 . Physical examination revealed nystagmus, intention tremor, absence of abdominal reflexes, bilateral Babinski sign and pallor of the optic disks. ${ }^{26}$

There are eight other cases in my records which began, respectively, at $14,15,16$ and 17 years. The histories of three of these are not reliable, and the diagnoses are doubtful. There remain five cases, one in a patient of 14 , two of 16 and two of 17 , in whom the clinical diagnosis of multiple sclerosis was not to be questioned. As the period of childhood cannot be stretched beyond 15 years, there remains only one other case of 14 which may be included in the group of early multiple sclerosis. We have, then, four cases occurring in a total of 197 children, or 2 per cent.

From this study one may draw a fairly definite conclusion as to the existence of multiple sclerosis in children. The vast majority of

25. Schlesinger, Hermann: Zur Frage der akuten multiplen Sklerose und der Encephalomyelitis disseminata im Kindesalter. Arbeiten aus dem Neurologischen Institut. Wien. 17:410, 1908-1909.

26. These cases will be reported at greater length in a special paper on "Multiple Sclerosis in Children." 
cases stand unproved. In those instances the diagnoses were erroneous; yet it is difficult to explain why careful observers should have attempted to prove the existence of in fantile multiple sclerosis by means of doubtful cases. Those were very likely atypical, but could be better explained by the diagnosis of congenital disseminated syphilis, various traumatic birth palsies, spastic diplegias, Little's or Foerster's types of disease, family spastic paralysis, Friedreich's disease, tumors of the brain, hysteria, encephalomyelitis and cerebral sclerosis. Nevertheless, a few authentic cases remain. These have been proved, both clinically and pathologically, to have been multiple sclerosis. Its existence, therefore, in children, while rare and in need of scrutiny, cannot be doubted.

FAMILIAL, CONGENITAL AND HEREDITARY MULTIPLE SCLEROSIS

The question of familial, congenital and hereditary influence in disease in general and multiple sclerosis in particular is in need of strict definition. Loose interpretation of the meaning of those terms is responsible for many broad and erroneous conclusions. To speak of a congenital or hereditary predisposition, while possibly permissible, is not very meaningful. In order that a disease be considered congenital one must prove its existence in the parent at the time of or subsequent to inpregnation, that it was transmitted to the germ p'asm or embryo or fetus in utero and that it was present in the child at birth, although it need not have manifested itself immediately afterward. So, too, to speak of heredity one must show that the disease existed in some of the ascendants and collaterals, that it manifested itself in the descendants and that it affected the various persons with a fair degree of consistency or regularity. True mendelism will not accept, of course, an interpretation of heredity which does not conform to its laws. Further, one isolated instance cannot be accepted as proof of a general conclusion because there are too many possibilities by the law of chance, among so many hundreds and thousands of cases, that the disease may appear hereditary. The same may be said, although with less emphasis, about familial influence in disease.

There are, moreover, two distinct notions of hereditary or familial influence in nervous diseases which are current in medical literature. The older, which is gradually being discarded, is to consider any nervous disease in the family as a possible influence on or cause of any other nervous disease. Thus it is not unusual to find epilepsy, alcoholism, insanity, hysteria, neurasthenia, fright and exhaustion mentioned as possible hereditary (!) causes of multiple sclerosis. The more recent view, of course, and perhaps sounder, is to accept only the given disease in the consideration of familial, hereditary and congenital factors. 
Whether or not these factors operate in multiple sclerosis cannot be definitely answered, but there are numerous instances in which the disease occurred in parent and offspring. Among my own records there is one instance in nearly 200 cases; it is that of a woman of 55 who had multiple sclerosis, which began at 50 , whose son died from the same disease at 22 . This instance cannot be looked on as congenital as the mother developed the disease twenty years after the birth of her son.

Eichhorst cites a case in which there may have been a congenital factor. A woman who had typical multiple sclerosis for two years gave birth to a child who developed the disease. The mother died at 42 and the child at 9. Necropsy showed a typical sclerosis of the cord. Two children born before their mother had the disease did not have it. Pelizaüs ${ }^{2 i}$ reports an hereditary disease which occurred in three generations of males and was transmitted through the mother. It showed itself in one son, three grandsons and one great grandson. Pelizaüs believes that the disease was multiple sclerosis. The clinical picture was the same in all cases and came on at the same ages in all. There was bilateral nystagmus, speech disturbances, spastic paraplegia without atrophy, increased reflexes, intact sensibility and moderate dementia. Although persual of the clinical histories does not altogether convince one, Pelizaïs seems to be of the opinion that all were cases of multiple sclerosis.

Klausner ${ }^{28}$ reports two cases in a brother and sister of 25 and 27 years, respectively. Weisenburg reports two cases in a brother and sister, whom he personally observed, and a third member of the same family who is said to have suffered from the disease. The brother developed the disease at 15 and the sister at 4 . The family was English. Reynolds ${ }^{2: 1}$ reports three cases, the second, fourth and sixth in one family, a sister and two brothers of 33,30 and 27 years, respectively. The parents were psychopathic. He further quotes another English family in whom the first and third developed multiple sclerosis at 25 and 15 years, respectively. Frerichs and Erb (quoted by Borst) mention the disease in siblings, Totzke in two sisters of 11 and 14 years and Elta in mother and son. Among the records of the Montefiore Hospital are found two instances in which the disease occurred in brother and sister.

27. Pelizaüs, F.: Ueber eine eigentümliche Form spastischer Lähmung mit cerebralerscheinungen auf hereditärer Grundlage, Arch. f. Psychiat. 16:1885.

28. Klausner, Irma: Ein Beitrag zur Aetiologie der multiplen Sklerose, Arch. f. Psychiat. 34:841, 1901.

29. Reynolds, E. S.: Some Cases of Family Disseminated Sclerosis, Brain 27: 1904 . 
Merzbacher ${ }^{30}$ reports the case of a family with eleven members in whom a disease very much like multpile sclerosis developed in the fourth month of the lives of the persons. The patients had nystagmus and tremor of the head. One came to necropsy at the age of 20 and on microscopic examination the myelin sheaths were found totally absent. No extensive description is given. Coriat ${ }^{31}$ reports a peculiar form of family nervous disease resembling multiple sclerosis occurring in children. There were four patients of Russian Hebrew parentage, two of them being $a$ brother and sister, one a boy of 18 and one a girl of 8 .

From these cases it may be seen that the evidence is not conclusive. Eichhorst's isolated instance may be looked on as possibly illustrating congenital transmission. The numerous other instances in which the disease occurred in more than one member of a family or in parent and offspring cannot be considered, in view of its comparative prevalence, as absolute proof of familial and hereditary forms of multiple sclerosis. In this connection, too, one need consider the relation of the experimental investigations as to the etiology of multiple sclerosis. This disease has come to be looked on as the result of a subacute or chronic infection, and the gliosis has been interpreted as a reaction to inflammation. Obviously it makes some difference so far as this discussion is concerned whether the inevitable focal infection plays any causative rôle or a spirochete is the etiologic factor or "abiotrophy" and "systemic degeneration" are invoked to explain the genesis of the disease. It is quite possible, however, that the discovery of the causative agent of multiple sclerosis will clear up the question of the existence of familial, hereditary and congenital types.

\section{PSYCHIC AND MENTAL DISTURBANCES}

Attention has commonly been called to the existence of psychic and, more especially, emotional disturbances in multiple sclerosis, and numerous reports of cases in which the patients showed those symptoms are to be found alike in American and European literature. Comparatively fewer statistical facts bearing on mental symptoms exist in American literature, whereas a number of European writers have reported extensively on this subject. In many cases it is not easy to draw a sharp line between mental and psychic symptoms. Oppenheim, for instance, looks on the impulsive laughter occasionally found in multiple sclerosis as a neurologic sign of thalamic involvement and not as a psychic symptom as commonly understood.

30. Merzbacher: Eine eigenartige familiäre Erkrankung des Zentralnervensystems, Neurol. Centralbl. 26:1139, 1907.

31. Coriat, Isador: A Peculiar Form of Family Nervous Disease Resembling Multiple Sclerosis Occurring in Children, Boston M. \& S. J. 160:506, 1909. 
Under psychic symptoms are mentioned general nervousness, irritability, sleeplessness, mild depression, lack of concentration, emotional or affective disturbances. While these symptoms are commonly encountered, they cannot be said to be characteristic of multiple sclerosis. Many patients, however, show graver disturbances, and indeed to such an extent as to dominate the whole clinical picture and to lead to erroneous diagnoses. This is especially true of hysteria. More rarely hysteria simulates multiple sclerosis. Thus Parhon and Goldstein ${ }^{32}$ mention a case of hysteria which simulated multiple sclerosis so closely that the diagnosis was made only at necropsy. Zilgien ${ }^{33}$ reports the case of a young man of 23 who for two years had hysterical symptoms, stammering and laughter, and was ultimately proved to have multiple sclerosis. The same author also speaks of a woman of 33 who for four years, up to the time of her complete recovery, was looked on as having multiple sclerosis. Healey ${ }^{34}$ reported a case in which the diagnosis between multiple sclerosis and hysteria was doubt ful for a long time.

Mendel believes that psychic symptoms are present in all cases of multiple sclerosis and Lannois is convinced that they occur quite regularly (quoted by Raecke ${ }^{35}$ ). Berger ${ }^{36}$ mentions nervousness as occurring in nineteen, or 9 per cent., of his cases and pronounced psychic disturbances, such as irritability, depression, memory defects in twenty-four, or 12 per cent. Incidentally he mentions three cases of epilepsy in his 206 cases. Fourteen of his patients showed irritability, eight mild depression, four euphoria and eighteen mild memory defects. Morawitz mentions memory weakness in eight of thirty-three cases.

Next to hysteria, paresis is said to occasion diagnostic difficulties. Raymond and Touchard ${ }^{37}$ report a case of multiple sclerosis which began with symptoms simulating general paresis. The patient had epileptiform attacks, change of character, defective memory and disturbances of speech. It is well known, of course, that paresis may for a time simulate multiple sclerosis. I have even now a patient under observation whose symptoms for many months consisted of spastic

32. Parhon and Goldstein: Un cas d'Hysterie simulant la sclérose en plaque et la syringomyelie, Rev. neurol. 13:862, 1905.

33. Zilgien, H.: De l'importance des symptôms hystériques dans l'étude de la pathogénie et du diagnostique de la sclérose en plaque, Rev. méd. de l'Est. 37: $673,1905$.

34. Healey, W., Jr.: J. Nerv. \& Ment. Dis. 36:164, 1509.

35. Raecke: Psychische Störungen bei der multiplen Sklerose, Arch. f. Psychiat. 41:482, 1906.

36. Berger, Arthur: Eine Statistik über 206 Falle von multipler Sklerose, Jahrb. f. Psychiat. u. Neurol. 25:168, 1905.

37. Raymond and Touchard: Sclérose en plaque debutant par des troubles mentaux simulant la paralysie général, Rev. neurol. 17:224, 1909. 
paraplegia, ataxia, tremor, nystagmus and scanning speech. It was only after many months that pupilary changes and mental deterioration called attention to the paretic picture. The diagnosis was confirmed by the positive Wassermann reaction in the blood and spinal fluid. Geay, ${ }^{38}$ in speaking of psychic symptoms in multiple sclerosis, stresses the point that the disease is mostly to be differentiated from hysteria and paresis and concludes that the mental symptoms may range from simple enfeeblement of memory to complete obnubilation. Spiller and Camp ${ }^{39}$ reported a patient (the case came to necropsy) with suicidal tendencies. Charcot early called attention to dulness, indifference, slowness to grasp things and delusions, besides memory weakness and impulsive laughter. Probst found a few patients (five out of fiftyeight) with high grade dementia.

Raecke has made an excellent study of psychic and mental symptoms in multiple sclerosis. He reviewed the literature extensively and included a review of thirty-seven cases of his own. He states that thirteen patients showed definite dementia and nine others psychic disturbances. The initial symptoms usually were depressive and maniacal, with, at times, delirial episodes. The latter were particularly to be found in patients with convulsions. Affective disturbances were common. He quotes a number of authors on the subject. Thus, Gowers spoke of rare cases of insanity based on multip'e sclerosis. Redlich mentions idiocy, confusion, irritability and hallucination as being more common in multiple sclerosis than was formerly believed. Meinert speaks of general disturbances of intellect and enumerates eroticism, irritability, memory weakness, melancholia, depression, insomnia, euphoria, paranoidal delusions and suicidal trends as possible mental symptoms. Oppenheim, on the other hand, believes that high grade dementia and delusions are uncommon in multiple sclerosis. Seiffer ${ }^{40}$ also made a comprehensive study of mental disturbances in multiple sclerosis. His conclusions are: 1 . The disease may be totally free from mental symptoms. 2. The longer the duration of the disease the more likely and the more pronounced the disturbances of intelligence. 3. There is no correspondence between the intelligence defect and the educational level of the patient. 4. There is a close connection between the intelligence defect and the clinical type of the disease, patients with cerebral defects giving the most symptoms and those with spinal signs fewest or none. 5. The dementia of multiple sclerosis

38. Geay, A.: Des trouble psychique dans la sclérose en plaque, Thése de Lyon, 1904; Rev. neurol. 13:S00, 1905.

39. Spiller, W. G., and Camp, C. D.: Multiple Sclerosis with a Report of Two Additional Cases, with Necropsy, J. Nerv. \& Ment. Dis., July, 1904.

40. Seiffer, W.: Ueber psychische, insbesondere Inteligenzstörungen bei multipler Sklerose, Arch. f. Psychiat. u. Nervenkrank. 15: 1905. 
cannot be strongly differentiated from other dementias though that of the former shows great liability of mood. These sudden changes are quantitatively high and stand in no relation to the degree of dementia.

In the records of my own cases little mention is made of outspoken organic mental changes. Psychic symptoms, such as irritability, depression and general nervousness, mild memory defects and emotional changes are frequently noted. Impulsive laughter and euphoria are occasionally referred to. Hysteria seems not infrequently to have been considered as an alternate diagnosis for a time. Marked dementia was rarely encountered, delusions and hallucination practically not at all. Considering that a great many of these patients had the disease for years and years and that quite a number were inmates of the Montefiore Hospital for a very long time, it is noteworthy how few showed definite mental symptoms. In none of the cases recorded was there a complete psychosis or organic dementia. ${ }^{41}$

41. In addition to the references given, the following may be of interest: Abrahamson, L.: Familial Multiple Sclerosis, J. Nerv. \& Ment. Dis. 33: 1906. Batten, F. E.: Proc. Roy. Soc. 22:35, 1908-1509.

New York Neurological Society Meeting, Feb. 4, 1502, J. Nerv. \& Ment. Dis. 29:288, 1902.

Tredgold, A. F.: Rev. Neurol \& Psychiat., Ju1y, 1904. 